\title{
Author Correction: Pan-cancer analysis of homozygous deletions in primary tumours uncovers rare tumour suppressors
}

\author{
Jiqiu Cheng 1,2, Jonas Demeulemeester (10) 3,4, David C. Wedge 5,6, Hans Kristian M. Vollan², Jason J. Pitt7,8, \\ Hege G. Russnes ${ }^{2,9}$, Bina P. Pandey ${ }^{1}$, Gro Nilsen ${ }^{10}$, Silje Nord², Graham R. Bignell ${ }^{5}$, Kevin P. White $7,11,12,13$, \\ Anne-Lise Børresen-Dale ${ }^{2}$, Peter J. Campbell ${ }^{5}$, Vessela N. Kristensen ${ }^{2}$, Michael R. Stratton ${ }^{5}$, \\ Ole Christian Lingjærde (iD ${ }^{10}$, Yves Moreau ${ }^{1} \&$ Peter Van Loo (i) ${ }^{3,4}$
}

Correction to: Nature Communications; https://doi.org/10.1038/s41467-017-01355-0; published online 31 October 2017.

The original version of this Article contained an error in the author affiliations.

The affiliation of Kevin P. White with Tempus Labs, Inc., Chicago, IL, USA was inadvertently omitted.

This has now been corrected in both the PDF and HTML versions of the Article.

Published online: 17 December 2018

\begin{abstract}
(c) Open Access This article is licensed under a Creative Commons Attribution 4.0 International License, which permits use, sharing, adaptation, distribution and reproduction in any medium or format, as long as you give appropriate credit to the original author(s) and the source, provide a link to the Creative Commons license, and indicate if changes were made. The images or other third party material in this article are included in the article's Creative Commons license, unless indicated otherwise in a credit line to the material. If material is not included in the article's Creative Commons license and your intended use is not permitted by statutory regulation or exceeds the permitted use, you will need to obtain permission directly from the copyright holder. To view a copy of this license, visit http://creativecommons.org/licenses/by/4.0/.
\end{abstract}

(c) The Author(s) 2018

\footnotetext{
${ }^{1}$ Department of Electrical Engineering (ESAT) and iMinds Future Health Department, University of Leuven, Kasteelpark Arenberg 10, B-3001 Leuven, Belgium. ${ }^{2}$ Department of Genetics, Institute for Cancer Research, Oslo University Hospital Radiumhospitalet, N-0310 Oslo, Norway. ${ }^{3}$ The Francis Crick Institute, 1 Midland Road, London NW1 1AT, UK. ${ }^{4}$ Department of Human Genetics, University of Leuven, Herestraat 49, B-3000 Leuven, Belgium. ${ }^{5}$ Wellcome Trust Sanger Institute, Hinxton, Cambridge CB10 1SA, UK. ${ }^{6}$ Big Data Institute, University of Oxford, Old Road, Oxford OX3 7LF, UK. ${ }^{7}$ Institute for Genomics and Systems Biology, University of Chicago, 900 East 57th Street, Chicago, IL 60637, USA. ${ }^{8}$ Committee on Genetics, Genomics, and Systems Biology, University of Chicago, 920 East 58th Street, Chicago, IL 60637, USA. ${ }^{9}$ Department of Pathology, Oslo University Hospital Radiumhospitalet, N-0310 Oslo, Norway. ${ }^{10}$ Department of Informatics and Centre for Cancer Biomedicine, University of Oslo, N-0424 Oslo, Norway. ${ }^{11}$ Department of Ecology and Evolution, University of Chicago, 1101 East 57th Street, Chicago, IL 60637, USA. ${ }^{12}$ Department of Human Genetics, University of Chicago, 920 East 58th Street, Chicago, IL 60637, USA. ${ }^{13}$ Tempus Labs, Inc., Chicago, IL, USA. Correspondence and requests for materials should be addressed to P.V.L. (email: Peter.VanLoo@crick.ac.uk)
} 